\title{
VITAL STAINING OF TRICHOMONAS VAGINALIS WITH FLUORESCEIN*
}

\author{
BY \\ WALDEMAR E. COUTTS and EDNA SILVA-INZUNZA \\ Urological Clinic, José Joaquin Aguirre Clinical Hospital Medical College, \\ University of Chile
}

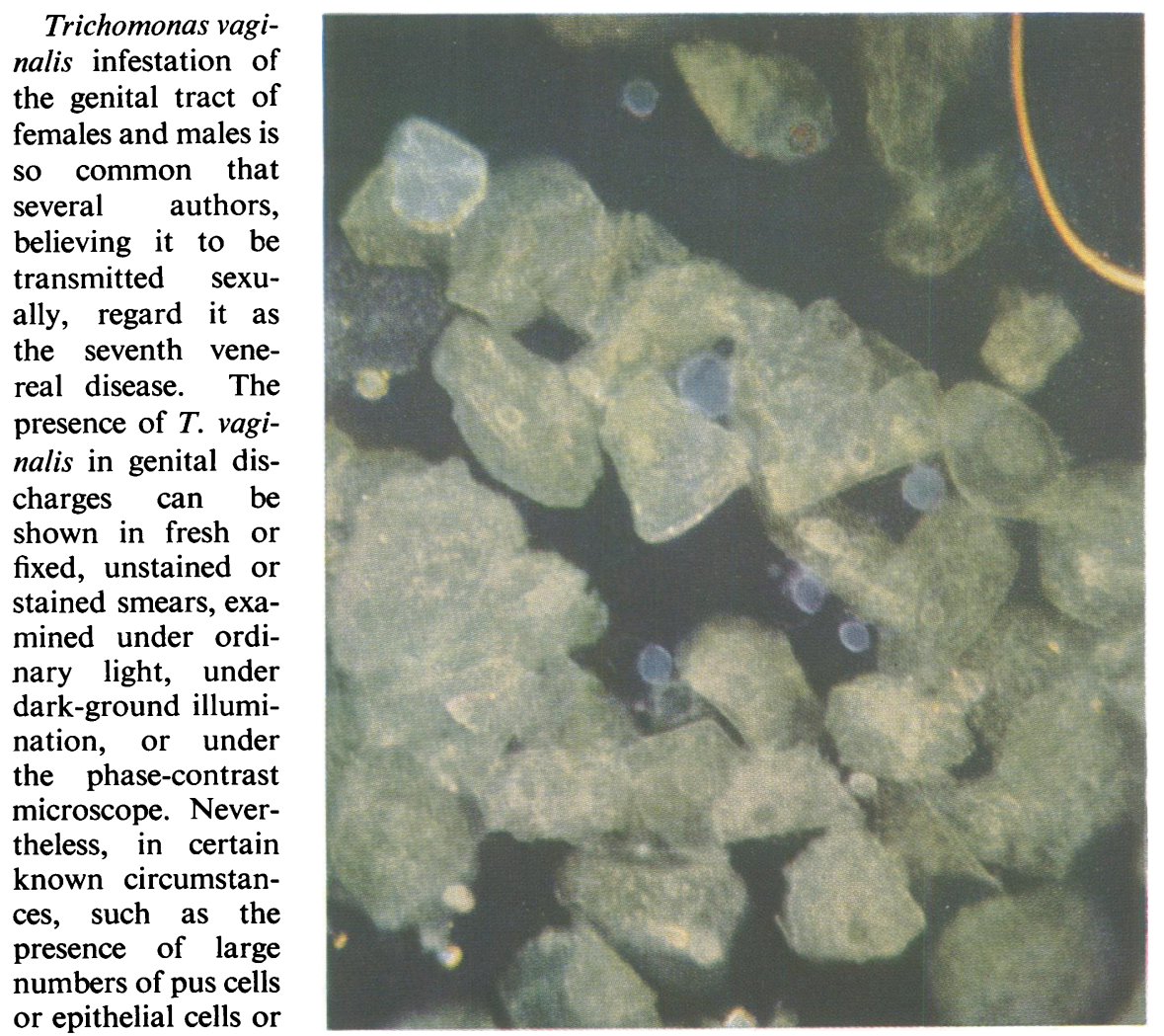

by capillary action under the cover-glass of a freshly prepared specimen. Within a few seconds all evolutive forms develop a bright emerald green colour which gradually changes to a blue-green as shown in the accompanying Figure. Trophozoites preserve the movement of both flagellae and the undulating membrane which do not stain. Preparations are best examined under darkground illumination.

To obtain a fixed preparation, 10 per cent. formol is introduced under the cover-glass $10 \mathrm{~min}$ utes after the introduction of the fluorescein, and is allowed to act for 10 minutes. The cover-glass is then removed and the material spread on the slide in a thin film. Dead trophozoites both, the organism is difficult to identify unless the secretions are diluted with normal saline solution. Apart from these conditions, there are also occasions when $T$. vaginalis, although present, may escape detection, as when macro- or micro-globoid bodies or cystic forms predominate and trophozoites are practically absent.

\section{Method}

The presence of these evolutive forms of $T$. vaginalis can be demonstrated by allowing a few drops of a 5 per cent. aqueous solution of fluorescein to penetrate

* Received for publication August 5, 1953. and evolutive forms do not stain in the presence of fluorescein.

With this staining method it is not necessary to dilute preparations, even although many pus or epithelial cells are present ; both the trophozoites and the evolutive forms of $T$. vaginalis rapidly take up the emerald green colour, while any other elements in the preparation take a long time to absorb any fluorescein. Using this staining method as a routine in the examination of genital discharges, we have increased the incidence of positive results. We believe that other workers will also have this experience with this simple and reliable diagnostic procedure. 